\title{
Examining the Effect of the Organization's Internal Control System on Organizational Effectiveness: A Jordanian Empirical Study
}

\author{
Buthayna Mahadeen ${ }^{1}$, Rand Hani Al-Dmour ${ }^{2}$, Bader Yousef Obeidat ${ }^{1} \&$ Ali Tarhini $^{3}$ \\ ${ }^{1}$ Department of Business Management, The University of Jordan, Amman, Jordan \\ ${ }^{2}$ Department of Management Information Systems, The University of Jordan, Amman, Jordan \\ ${ }^{3}$ College of Economics and Political Science, Department of Information Systems, Sultan Qaboos University, \\ Muscat, Sultanate of Oman \\ Correspondence: Ali Tarhini, College of Economics and Political Science, Department of Information Systems, \\ Sultan Qaboos University, Muscat, Sultanate of Oman. Tel: 974-5012-1922.
}

Received: September 5, 2016

Accepted: September 22, 2016

Online Published: November 2, 2016

doi:10.5430/ijba.v7n6p22

URL: http://dx.doi.org/10.5430/ijba.v7n6p22

\begin{abstract}
This study aims to investigate the impact of the internal control system (Control environment, Communication, Risk management, Control activities and Monitoring) on organizational effectiveness in Jordan. The organizational effectiveness was studied through three approaches namely; organizational ability to achieve its goals (Goal approach), organizational ability to control and maintain the needed resources (Resource Control approach) and the (Multiple Constituency approach) which deals with organizational competitiveness, job satisfaction, customer satisfaction and complaints. To achieve the objectives of the study, a theoretical framework was developed and some hypotheses were proposed. Data were collected using a self-administrated questionnaire from 151 employees occupying different managerial levels in Jordan. The results of the multiple regression test showed a high positive impact of the study variables on organizational effectiveness with $(\mathrm{R}=87.9 \%)$ and ( $\mathrm{R}$ square $=77.3 \%)$. Based on the findings of the research, the researchers suggest a number of relevant recommendations related to improving awareness about the importance of internal control system components, and mechanisms to improve internal procedures and processes for improving the organizations' effectiveness using different approaches. The implications to both theory and practice are discussed at the end of this paper.
\end{abstract}

Keywords: organizational effectiveness, internal control system, management, Jordan

\section{Introduction}

As organizations today face increasingly complex, dynamic, and threatening environments, attention has been focused on both the running of day to-day business affairs and the adaptation of the organization to changing environmental conditions (Obeidat et al., 2016; Al-Sarayrah et al., 2016), and therefore on how to enhance performance through improved effectiveness, efficiency and flexibility (Orozco et al., 2015). Internal control systems approach is the approach that allows managers to evaluate how effectively an organization functions and how its resources operate (Shannak et al., 2012). Internal control helps bring order, direction and consistency to our organizations (Masa'deh et al., 2014). An effective system of internal control can give managers the means to provide accountability for their programs, as well as the means to obtain reasonable assurance that the programs they manage meet established goals and objectives (Al-Syaidh et al., 2015; El-Masri et al., 2015).

Generally speaking, organizations in the business sector in the Hashemite Kingdom of Jordan suffer from low level of achievement (Masa'deh et al., 2016). This issue is addressed very often and at several levels within the country (Almajali et al., 2016), in spite of the fact that Jordanian human resources are of the best skills in the region and of Jordan's remarkable reputation in several fields for example the ICT and regulatory sectors (Kateb et al., 2014; Obeidat et al., 2016; Altamony et al., 2016). The internal control system consists of all the variables that may contribute some way or another to the success or failure of any organization and by establishing a robust internal control system the organization promotes efficient and effective operations to produce quality products and services that are consistent with its objectives and goals (Agbejule \& Jokipii, 2009).

This research adopts a holistic view of the internal control system model as defined by the Office of Internal Controls 
/ State University of New York, and discusses its impact on the Organizational Effectiveness in Jordan. Accordingly, this study provides a holistic perspective by addressing all internal control system components at once, while previous studies focused on one or two components or even sub parameters in a component. Specifically, this research examines the five components of the internal control system (Control Environment, Communication, Risk Assessment, Control Activities and Monitoring) as independent variables and their impact on the three approaches of Organizational Effectiveness (Goal Approach, Resource Control Approach and Multiple Constituency Approach). Hence, this study aims to examine to what extent does the internal control system in Jordanian organizations contribute to the achievement of the organization's objectives?. This study contributes to the knowledge by extending the existing literature on the internal control systems and organizational effectiveness locally as there is a lack of national studies covering this topic in its holistic perspective in Jordan. This study will provide some practical solutions to overcome any gaps in any control system components, in order to improve organizational effectiveness.

\section{Literature Review}

By definition, Internal control or an Internal Control System is the" integration of the activities, plans, attitudes, policies, and efforts of the people of an organization working together to provide reasonable assurance that the organization will achieve its objectives and mission". (Office of internal controls, state university of New York).

By establishing a sound internal control system, the organization promotes efficient and effective business processes that are able to produce quality products/services convenient with the organization's mission. It also preserves resources against loss due to waste by ensuring adherence to laws / regulations/ contracts and management directives. As a result, the internal control systems develop and maintain reliable financial and management data in a timely reporting system (Hanim et al., 2005). There are five components of the internal control system namely control environment, communication, risk assessment, control activities and monitoring:

Control Environment: the control environment sets the tone of an organization, influencing the control consciousness of its people (Leung et al., 2011). It is the foundation for all other components of internal control, providing discipline and structure. Control environment factors include the integrity, ethical values and competence of the entity's people; management's philosophy and operating style; the way management assigns authority and responsibility, and organizes and develops its people (Eldridge et al., 2013).

Communication: Communication can be defined as the process of transmitting information and common understanding from one person to another (Keyton, 2011). The word communication is derived from the Latin word, (communis) which means common. The definition suggests the fact that unless a common understanding results from the exchange of information, there is no communication (Lunenburg, 2010). Communication channels are developed in organizations between all members of the organization and to communicate relevant information to the right people in a timely way.

Risk management: Risk management in business it is sometimes referred to as Enterprise Risk Management (ERM), is the process of planning, organizing, leading, and controlling the activities of an organization in order to minimize the effects of risk on an organization's capital and earnings (Little, 2013). Enterprise risk management expands the process to include not just risks associated with accidental losses, but also financial, strategic, operational, and other risks (Little, 2013). Risk management is about identifying all internal and external risks in the organization in terms of its significance, likelihood and cause, and establishing plans to prevent/reduce/avoid the occurrence of these risks. Risk significance is a measure of the magnitude of the risk effect if the unfavorable event were to occur. The effect is the ultimate harm that may be done or the opportunity that may be lost that should be quantified if possible. Likelihood is the probability that an unfavorable event would occur if there were no control activities to prevent or reduce the risk from occurring (Dionne, 2013).

Control Activities, Management policies and procedures: Applied in achieving a firm's objectives, protection of its assets, and measurement of its performance (Elahi, 2013). Organizations should establish control activities - both manual and automated - to effectively and efficiently accomplish the organization's objectives and mission and to reduce the risks that can hinder their achievement in addition to dealing with any exceptional / undesired event promptly and appropriately as soon as it is noticed.

Monitoring: Monitoring can be defined as a continuing function that aims primarily to provide the management and main stakeholders with early indications of positive or negative progress, in the achievement of objectives. Monitoring helps organizations to assess the quality of performance over time and determine the efficiency of its controls. This process also assists timely decision making, ensure accountability, and provide the basis for evaluation and learning (Sera and Beaudry, 2007; Masa'deh et al., 2015; Obeidat et al., 2016). 
Organizational effectiveness: an organization is effective if it is being able to meet its objectives subject to certain constraints and produce a desired effect without waste and with minimum expenditure of its resources. It's about aligning and engaging their people, the management systems, and the structure and capabilities (including organizational culture) to the strategy (Haid et al., 2010). Organizational effectiveness is an abstract concept and is difficult for many organizations to measure directly. Instead of measuring organizational effectiveness directly, the organization selects proxy measures to represent effectiveness. Proxy measures may include measuring the number of people served, types and sizes of population segments served, and the demand within those segments for the services the organization supplies.

The following subsections summarizes the research and studies found in the literature that discussed the components of this study.

\subsection{Internal Control System}

Earlier discussion in prospector firms, about the relationship between strategy, control activities, monitoring and effectiveness, indicated that high degrees of internal control activity and low degrees of monitoring ensure a greater effectiveness of the internal control system. On the other hand, for analyzers a high degree of internal control activity and high degrees of monitoring lead to a highly effective internal control system. There were no significant differences between defenders and analyzers in those firms (Adebayo et al., 2009).

As the overall internal control system showed an average level of effectiveness, this implied an overall low level of effectiveness. Of the five categories assessed under internal control system, control environment showed a higher level of effectiveness (Onumah et al. 2012).

Organizational effectiveness and commitment through strategic management showed two major conclusions. First, the organization under observation did behave by doing what it said it did. The expressed goal (what the organization says it is doing) matches its operative goals (what the organization is actually doing). The organization under study both in theory and practice was number one. Quality also was perceived in the manner that top management indicated. The second conclusion is that the strategic management processes related to planning, namely flexibility and goal setting, were in combination the highest rated of the five strategic management processes.

The significant aspect of the study was that the authors were able to be part of the organization that was under observation and through which data were collected. This was indeed a special opportunity to the researchers to test their theory in a day-to-day management scenario.

The many members of the organization who participated in the study and the data collection were all particularly interested in the theoretical aspects of organizational effectiveness and commitment through strategic management.

The key processes of strategic management planning, analysis, decision making, implementation, and evaluation were made real in the organization and this was manifested in the organization through commitment to doing what it said it was doing. There is a possibility that effectiveness is more a measure of commitment with or without some of the sophisticated aspects of organization effectiveness. When the entire organization is committed to the same mission, goals, and objectives then indeed we have an effective organization (Thibodeaux et al. 1996).

\subsection{Environment}

The balance between trust and control showed that trust and control are either substituting or complementing each other. Further, it is found that the complementary/substitution debate represents this relation as an interactive process, and not static or isolated concepts (Jagd, 2010). Traditional approaches of management were built upon the assumption that if organizational goals were to be achieved, close control of the work and behavior of the lower ranks is constantly needed, and these views still have resonance today. However, changes in the business environment, work and organizational forms have all increased the need to manage at a distance, to seek commitment from every individual and to facilitate the utilization of intangible resources such as tacit knowledge. Within this context, trust has been argued to grant benefits to the organization, including competitive advantage (Fairholm and Fairholm, 1999), individual and organizational effectiveness (Roy and Dugal, 1998) and the creation of commitment (Lamsa and Savolainen, 2000). Yet, there still remains a need for accountability, both internal and external, which necessitates the implementation of control systems and procedures. It is clear that these control procedures are firmly grounded in the relationships between individuals and groups at various levels within and between institutions. External demands for accountability, such as those resulting from failures of the corporate governance system, may lead to imposing of internal control processes which depend crucially on trust. In consequence, the misunderstanding of the relationship between control and trust may damage the effectiveness of such processes (Skinner et al. 2003). 
The roles of organizational justice and trust was examined in a specific type of management control system (MCS), which is the gain-sharing or profit distribution. According to the proposed theory, employee expectations of the level of justice in the gain-sharing distributive plan influence employee trust in managers. Positive perceptions of fairness lead to high trust, which, in turn has positive consequences for the organization such as lower employee turnover. Therefore, trust is linked to employee turnover intentions. Results imply that the organizational justice of an MCS has consequences for the attitudes and behaviors of employees and thus the success or failure of the MCS (Kennedy et al. 2009).

The relationship between outcome-based control system and unethical behavior was dependent on ethical climate, personality traits, and internal communications. It was shown that ethical climate was likely a stronger contributor to ethical behavior. While the empirical research did not provide a complete positive link between outcome-based control systems and unethical behavior, it did show that the relationship could exist and was dependent often upon other factors, such as the ethical environment of the organization (Appelbaum et al. 2005).

Sparrow et al. (2014) discussed the topics of changing strategy, business model, organization design, talent management, agile and resilient organization, balanced scorecard, employee engagement, advocacy and reputation by drawing upon frameworks that have previously arisen. He argued the need to combine human resource management perspectives with decision sciences, supply chain management, operations management, consumer behavior, innovation, management knowledge, strategic management and paying attention to the resource-based view of the firm, dynamic capabilities, business models and strategy as practice (Sparrow et al. 2014).

By examining the association between the use of three types of controls (input, behavior and output) with the level of employee's organizational commitment (EOC) across organizational life cycle (OLC) stages, it was found that the level of (EOC) was found to be highest in growth and revival stage units, suggesting that (EOC) relates to the level of innovation. The analysis revealed that the types of controls were significantly associated with the level of (EOC). In particular, a significant positive association was found between input controls and the level of (EOC) in both the birth and revival stages (SU et al., 2015).

The most important parameters contributing to a good control environment are ethical values and integrity, which form the standards for employees' conduct in taking proper daily decisions. If managers fail to communicate such values, or don't implement them themselves, this could weaken the organization's ability to accomplish its mission.

Management encourages integrity by:

- Establishing and publishing a code of conduct

- Complying with the organization's ethical values and code of conduct

- Rewarding employee commitment to the organization's ethical values

- Establishing methods for reporting ethical violations

- Consistently enforcing disciplinary practices for all ethical violations.

Competence is having the skill, knowledge and ability to perform a task. Management's responsibility for ensuring the competency of its personnel should begin with establishing appropriate human resource policies and practices.

Morale is the attitude people have about their work, as shown by their discipline and willingness to perform tasks. Management should be aware of the importance of good morale in an effective control environment and should take actions to maintain its high level, such as (Levine, 1996):

- Their opinions and contributions are welcomed and valued

- The organization is willing to help improve their level of competency

- There is opportunity for continuous improvement

- They have a part in the mission, goals and objectives of the organization

- The organization's appraisal and reward systems are fair

- The lines of communication are open

\subsection{Communication}

According to Sharma and Patterson (1999), effective communications must include both the formal and informal contact between the employees and the clients. They identify several elements of effective communications that include: 
- Empathy and listening skills

- Accurate explanations of fees and charges

- Being honest about risk and returns

- Educating the client to encourage more informed decisions.

Firms providing professional services to consumers need to think about how their communications appear to the potential customer. Advertising must be simple, accurate and friendly in tone. Staff should be trained in how to talk and listen to clients (Hajir et al, 2014). Sharma and Patterson (1999) identifies listening skills, empathy and politeness to be essential in training those people actually providing the service. These characteristics need to come across in all the communications between company and client from one side, and among employees themselves from another side. The intranet as a communication channel impact organizational effectiveness directly or indirectly, and a successful usage of intranet would definitely promote organizational success and effectiveness (Masrek et al. 2007).

By exploring the application of management control systems (MCS) to business processes for an organization operating in an uncertain environment, it was found that the organization responded to its uncertain environment with a package of formal and informal control systems for its strategically important business processes (Elahi, 2013). The relative importance of individual business processes was observed to positively influence the rigor of control systems' implementation (Eldridge et al., 2013).

A significant relationship exists between the constructs of "external environment" and "organizational culture", and therefore indicating that the environment extends a significant influence on planning, execution, control elements, and managers' characteristics and skills. There is also a significant relationship between the constructs of "organizational culture" and "management controls", thus indicating that organizational culture has a strong influence on the choice of management control systems in practice in the companies (Reginato et al., 2013).

\subsection{Risk Management}

International regulations began in the 1990s, financial institutions developed internal risk management models to protect themselves from unanticipated risks. At the same time, governance became essential, the concept of integrated risk management and risk manager position were created. The world's wake to numerous scandals and bankruptcies as a result of poor risk management, set the road for Sarbane-Oxeley's regulation in the USA in 2002. This regulation and other later stock exchange regulations, set the rules for governance, but did not prevent the financial crisis that began in 2007. Those regulations were not necessarily inefficient, rather than they were not applicable or enforced (Dionne, 2013).

In any business environment there is always a need to efficiently satisfy the diversified objectives of different stakeholders, and to find the balance between them in a pro-active and systemic way (Maqableh et al., 2014). The different configurations of stakeholders and their diverse objectives, knowledge, experience and authority influence the decision-making process, and may differ from operational, commercial or strategic perspectives and objectives. The balance between safety performance and operational performance depends on an organizational capacity and managerial capability to resolve potential conflicts between safety, efficiency and well-being of the organization (Beauchamp-Akatova et al., 2013).

In today's world, risk management is often perceived as a science, requiring the use of vary sophisticated and complex analytical tools. However, having risk management plans based on quantified probability and impact can result in the misleading belief of taking control of the organization's risks. In reality, the biggest threat to business is often the failure to implement a holistic, "art and science"- based approach to risk management, especially in the fast changing environment in which most firms now operate (Schroeder, 2014).

Being part of Project management plans, project teams often regard risk management simply as a paper exercise. As a result, these teams lose an opportunity to strengthen their projects and deliver the best possible project results (Little, A.D., 2013). There is much evidence that the current high level of uncertainty in the business world is going to get worse in the years to come. This trend and the resulting risks for businesses, demands a strategic level attention to risk management which can lead to competitive advantage (Elahi, 2013).

The global macro-economic environment can add a mixture of efficiency and complexity to business today. Technology although connecting us faster and easier, but adding an increased risk in maintaining the huge volumes of data and keeping them consistent. Regulatory requirements are increasing, both in terms of number and of specificity. Consumers are more informed and more demanding. Competitors are looking for ways to expand their 
market share at a time when growth remains low. Organizations recognize that an effective risk management function will most likely have a direct line to the top. As a result, $96 \%$ of risk management owners now report directly to the CEO. Organizations are also investing in staff and skills as part of their efforts to elevate the risk management function (Accenture, 2013).

\subsection{Control Activities}

There are many control activities managers can use to face the risks that threaten an organization's success. They can be grouped into four categories:

- Directive activities are used to guide an organization towards its desired goals. These take the form of laws, regulations, guidelines, policies and written procedures.

- Preventive activities are designed to avoid the occurrence of an undesirable event. Their development involves predicting problems before they occur and implementing ways to avoid them.

- Detective activities are designed to identify undesirable events and alert management about what has happened. This enables management to take corrective action promptly.

- Corrective activities are processes that focus on undesirable conditions until they are corrected. They may also help in setting up procedures to prevent recurrence.

The documentation of an organization's system of internal control should include the organization's structure, policies, assessable units, control objectives and control activities. The various aspects of a system of internal control can be represented in the form of policy and procedure manuals, and/or in the form of flowcharts or matrices (Levine, 1996). By studying the impact of internal audit on the internal control system, it was found that management of internal audit department; professional proficiency, objectivity and review significantly influence the monitoring aspect of the internal control system (Eldridge et al., 2013). Scope of work and performance of audit work significantly influences the information and communication aspect of the internal control system while performance of audit work, professional proficiency and objectivity significantly influence the control environment aspect of the internal control system. The management of internal audit department, performance of audit work, audit program and audit reporting significantly influences the risk assessment aspect of the internal control system. Finally, performance of audit work and audit reporting significantly influences the control activities aspect of the internal control system (Hanim et al. 2005).

The association between corporate governance guidelines and risk management and internal control practices found that a weaker focus on the importance of risk management and internal control in corporate governance guidelines does not encourage companies to further develop their risk management and internal control system. The specific content of corporate governance guidelines is an important variable to take into account when studying specific corporate governance practices, such as, in this case, risk management and internal control (Sarens et al .2010).

The "Management control system dilemma" which is about balancing sustainability with information overload, assures that the designers of management control system must consider the information overload before expanding the MCS to further include any social and nonfinancial disclosures. This expansion will likely result in overload for both information preparers and information users. The companies and CFOs will face an information overload dilemma in making these determinations, and that users will be overloaded in screening the widely increasing information that are being provided. It also noted the use of the balanced scorecard (BSC) as a tool to reflect and communicate multiple measures. As management control systems evolve to report sustainability data, increasing complexity and information overload will become exponentially problematic (Neumann et al. 2012). The management control systems can perform various coordinating and governance roles in managing new organizational forms. However, management control systems designers must be aware of the complexities of these new organizational arrangements (Tsamenyi, Cullen, 2010).

Organizational change provided a clear warning that organizational change is riskier than change initiators assume. Both the external environment and the internal dynamics of organizations determine the meaning of managerial practices. This implies that approaches taken to solve all internal issues altogether are doomed to fail (Jagd, 2010). Often, organizational change as a result of a high number of merger and acquisition deals fail in the post-integration stage or before completion. Most organizational change projects deal with less threatening results to organizational survival than mergers and acquisitions. Nevertheless, change projects with a smaller scope are also prone to poor planning, disappointing results and unintended consequences that divert resources from operational tasks, disrupt well-established routines, and shatter the trust of employees and business partners alike (Jacobs et al, 2013). 
By examining the accountability structures and the management relationships of internal audit highlighted the fact that there is a lack of correlation between the tasks performed by internal auditors and the important internal audit objectives, with the exception of internal control and risks. In regard to corporate governance processes, the results of the research indicate that internal control, risk assessment and management processes are regarded as the key factors for internal audit to contribute to good corporate governance (Leung et al., 2011).

\subsection{Monitoring}

Monitoring is the process of providing industrial managers with insight into the real-time progress of running processes (Sera \& Beaudry, 2007). This can be either as a periodic performance prediction or real-time business process monitoring. Gartner recently introduced a real-time enterprise paradigm; by placing the up-to-date information to the right people without delay for them to respond in real time this model has been widely embraced by companies to control the growing complexity of business processes (Kang et al, 2012). Such needs introduced the business process management system (BPMS), which has emerged as to enable the integrated enterprise management. BPMS is defined as an integrated information system to support design, modeling, execution, monitoring, analysis, evaluation, and re-engineering. BPMS has provided managers with an arrangement of business information from all aspect of organizations. The continuous monitoring of business performances measure and refine the business achievements, and is implemented by business activity monitoring (BAM) which is defined as an information system providing a real-time access to critical indicators in business operations (Kang et al., 2012).

Industrial managers monitor and analyze critical performance indicators in real time during the execution of business processes by using an extended formal concept analysis (FCA). This approach monitors the current progress of ongoing processes and periodically predicts their probable routes and performances. To sustain competitiveness in a rapidly changing business environment, has led to the adoption of real-time process monitoring systems in the business sector to support decision making and risk management during execution of the processes (Kang et al., 2011).

Transformative business sustainability (TBS) model aimed at assessing companies' efforts in application of the best business practices. It encourages systematized planning, and is designed to help managers conceptualize how stakeholders and sources can be used to generate value. It facilitates change and focuses on innovation in terms of business sustainability and the application of sustainable practices (Wagner et al., 2014).

\subsection{Organizational Effectiveness}

Recent studies focus on the determinants of organizational effectiveness such as culture (Liu et al., 2010; Lukas et al., 2013; Schneider et al., 2013). Also, organizational effectiveness is being studied in the contexts of product development and innovation (Büschgensa et al., 2013; Slater et al., 2014). High performance work systems (HPWS) may change the organizational effectiveness through changing the organization's intra-organizational social capital. The investments in human capital and in changing HR practice systems are all costly. Organizations need to perform a cost- benefit analysis in these kinds of decisions. Intra-organizational social capital is an important resource for all organizations, but is especially important for those organizations that are knowledge-intensive, which rely on individuals' commitment and motivation; this needs individuals' cooperation, and continuous innovation. In these organizations, social capital is extremely critical (Jiang et al. 2015).

Organizational Capability (OC) is defined as "the ability of an organization to use resources, material or non-material, with an effective way, in order to achieve its goals" (Xenidis et al., 2014). A global study found that fewer than half of all employees work in an organization where senior leaders effectively communicate the strategy. And even more worrying is that even fewer employees believe that senior leaders effectively implement the strategy (Haid et al., 2010). The resource-based view of TQM elements deal with quality management from a strategic viewpoint, or what is known as Strategic Quality Management (SQM), this is related to how the company utilizes its resources with minimum discrepancies between what is perceived to be needed by each strategy, and what is being actually allocated (Alidrisi et al., 2012).

Regarding job satisfaction, most research supports positive relationship between the level of education and job satisfaction, although sometimes, a negative relationship is found. A clarification of the association between educational level and job satisfaction resulted that higher educated workers are more satisfied than their lower educated counterparts, because they have a job of better quality. When one controls all the job characteristics, a negative relationship appears, with higher educated workers reporting less job satisfaction (Verhofstadt et al., 2007).

Customer satisfaction and complaint handling are important parts of any organization who seeks to understand the circumstances and emotions that make customer recovery programs successful. In the financial services sector, 
customer analysis continues to grow as the service providing often requires interaction between the customer and the company's employees. Although banks try to provide error-free services, service failures are quite frequent in the banking industry, with the subsequent reduction in customer satisfaction and, on occasions, customer complaint. As service failures, may cause the defection of intolerant customers, understanding the service recovery process could be fundamental. Although a service failure has the potential to destroy customers' loyalty, the successful implementation of service recovery strategies may prevent the defection of customers who experience a service failure. Consequently, it is important to understand what factors make customer recovery programs successful (Varela-Neira et al., 2010).

\section{Methodology}

\subsection{Theoretical Framework}

The internal control system is a concept of great importance in maintaining consistency, direction and discipline in firms and organizations of variable size. It is widely experienced in day-to-day activities, and provides managers with a means of assurance that the projects and programs they're handling meet the organizational goals and objectives. However, the responsibility of an effective internal control system rests on the shoulders of all members in the organization, those having supervisory ranks and supporting staff as well, and the level of its success or failure depends on the attention given by staff of all levels.

The internal control system also impacts every aspect in the organization and is a basic element that permeates the organization and not an added feature.

According to the International Organization of Supreme Audit Institutions, there are four specific purposes of internal control system:

1. To promote orderly, economical, efficient and effective operations and to produce quality products and services consistent with the organization's mission.

2. To safeguard resources against loss due to waste, abuse, mismanagement, errors and fraud.

3. To ensure adherence to laws, regulations, contracts and management directives.

4. To develop and maintain reliable financial and management data, and to accurately present that data in timely report.

In order for an organization to address the above purposes, it must establish a sound internal control system. Yet, a subject of such importance is not given the right attention and understanding and often misunderstood or undervalued. Not all organizations are aware of the impact of a sound internal control system on their effectiveness, although attention is made to some of its components in varying degrees. The key word here is "adequate integration". Organizations should work persistently to establish adequate integration between their different internal components to establish internal control system, which contributes greatly in accomplishing both strategic and operational goals.

This includes improving existing practices, activities, and regulations, if necessary, so as not to contradict or violate the obligations of the institution and the laws governing its work.

\subsubsection{Conceptual Definitions}

Following are the definitions of the variables and factors in this study:

1. Internal Control System: based on the adopted definition of the Office of internal controls / State University of New York, this research will study the five components of the internal control system as stated and defined in this part.

2. Control Environment: Control environment is the attitude of management and the employees of an organization toward internal control and control awareness established and sustained by them. It is a product of management's philosophy, style and supportive attitude, as well as the competence, ethical values, integrity, and morale of the organization's people. The organization structure and accountability relationships are key factors in the control environment. The control environment has a pervasive influence on all the decisions and activities of an organization. A positive control environment is the foundation for all other standards of internal control, by providing discipline, structure, accountability goal achievement and supporting of morale and integrity.

3. Communication: Good communication channels are essential tools that management should support to carry information to people who need it throughout the organization. The organization's management and staff should be able to use these established channels to communicate relevant information to the right people in a timely way. Clear 
internal communication channels:

- Inform employees of their duties and responsibilities.

- Report sensitive matters.

- Enable employees to provide suggestions for improvement.

- Provide the information necessary for all employees to carry out their responsibilities effectively.

- Convey top management's message that internal control responsibilities are important and should be taken seriously.

Management also needs to establish specific communication channels between the organization and external parties, like customers, suppliers and regulators, who also need reliable and timely information relevant to their specific needs.

Communication issues affect every aspect of an organization's operations, and help support its system of internal control. Therefore, the extent to which a good communication network is established and used by both managers and employees can help management circulate guidance about internal control issues. The feedback from this communication network can help management evaluate how well the various components of the system of internal control are working, and which features need improvement

4. Risk management: Management should estimate the likelihood for each identified risk. The cause of the risk is the reason why an unfavorable event may occur; this is why management should also define them. This information is critical if management is to design control activities that will effectively limit the risk and should be registered in a risk profile. This profile should be reviewed periodically by a specialized unit, who is also responsible of setting plans to prevent/reduce internal and external risks.

5. Control activities: Control activities are tools - both manual and automated - that help prevent or reduce the risks that can disrupt accomplishment of the organization's objectives and mission. These functional controls give an early warning whenever something exceptional happens to be dealt with promptly and appropriately. A basic and major factor in the control activities is having clear definition of personnel tasks and their special demands, in addition to authorizations and the delegation of power.

6. Monitoring: Monitoring is the day-to-day supervision of the organization's activities and transactions implementing. This role is to assess the quality of performance and to determine whether controls are effective. Automating this process facilitates the accurate reporting to the management to take swift corrective actions and guarantee achievement of the objectives. For monitoring to be most effective, all employees need to understand the organization's mission, objectives, and responsibilities and risk tolerance levels of their jobs.

7. Organizational effectiveness: This research depends on the definition of organizational effectiveness including the three approaches: the goal approach, the resource control approach and the multiple constituency approach.

- The Goal Approach: this approach views an organization as successful if its goals and objectives are satisfied. To be able to do that, management should have a reasonable assurance that the structure supports the planned goals and objectives. There should also be a comprehensive integration of activities and efforts of people in the organization that should eventually lead to quality products/services. Service recipients' studies should target a high level of customer satisfaction.

- The Resource Control approach: Simply stated if an organization wants to survive it needs to be able to attract the needed resources from the environment to produce its output. It is fundamental in this approach to ensure the staff's adherence to laws, regulations and contracts, and that management's decisions are based on timely financial and managerial reporting system. This approach is also concerned with the safeguarding and protection of different resources and assets against loss that might be due to errors, abuse, fraud or vandalism.

- The Multiple Constituency Approach: this approach is concerned with surviving against competitors; it also recognizes the varying interest of different groups and individuals within the organization. Periodical surveys should be scheduled to measure and target high level of job satisfaction among employees. Similar surveys should be performed to target high customer satisfaction and decline in clients' complaints.

It is important to note that measures of organizational effectiveness are value based and time specific. As such, over time the goals of different constituents will change and thus will the criteria for measuring organizational effectiveness. In summary, a working definition of organizational effectiveness is the maximum combined output of 
the primary constituents or input.

\subsubsection{Research Model and Hypotheses}

The following Figure 1 shows the proposed research model including all the variables and the hypothesized linkages as described earlier.

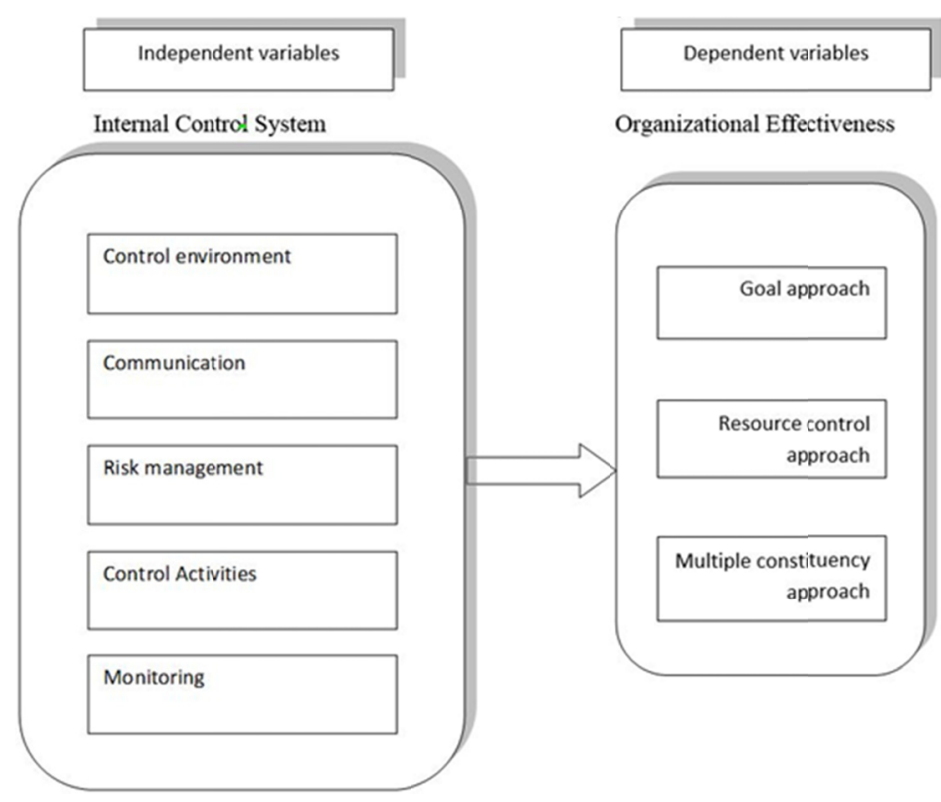

Figure 1. The proposed research model

This study aims to test the following hypotheses:

H0: There is no statistically significant impact at $(\alpha \leq 0.05)$ of the internal control system on the organizational effectiveness.

The following are the five sub-hypotheses:

H0-1: There is no statistically significant impact at $(\alpha \leq 0.05)$ of the environment on the organizational effectiveness.

H0-2: There is no statistically significant impact at $(\alpha \leq 0.05)$ of the communication on the organizational effectiveness.

H0-3: There is no statistically significant impact at $(\alpha \leq 0.05)$ of the risk management on the organizational effectiveness.

H0-4: There is no statistically significant impact at $(\alpha \leq 0.05)$ of the control activities on the organizational effectiveness.

H0-5: There is no statistically significant impact at $(\alpha \leq 0.05)$ of the monitoring on the organizational effectiveness.

\subsection{Research Procedure}

Data were collected from 151 Jordanian's top and middle managers using a self-administrated questionnaire using a convenience sampling technique. Before distributing the questionnaire to potential respondents, the questionnaire was sent to 5 specialized academics in the filed from different universities to ensure that it serves and achieves the research purpose. A pilot test was also conducted with 20 potential respondents to ensure validity and reliability of the questionnaire items. A questionnaire contacting 51 items measuring the internal control system components and organizational effectiveness approaches. These items were measured using 5 points Likert scale ranging from 1strongly disagree to 5- strongly agree. To test the reliability, Cronbach's alpha was used in this study to test reliability and consistency of the scale. All items were above the cut-off (0.7) and ranged between 0.87 and 0.94 which means that the items being measured have adequate reliability (Sekaran and Bougie, 2009). The questionnaire items and reliability results can be shown in Appendix 1 and 2. 


\section{Data Analysis}

\subsection{Demographic Analysis}

Among the returned 151 questionnaires, there was 81 (53.6\%) male and 69 (45.7\%) female. The highest participation percentage (44.4\%) was from the age group (30-39) years, while the lowest participation percentage (7.3\%) was from those within the age group $(>50)$ years. In addition, most of the respondents were those holding Bachelor degree (59.6\%). Furthermore, the employees were mostly having 6 to 10 years of experience $(41.7 \%)$. As for the organizational size, the results in Table 1 show that the highest percentage $(30.5 \%)$ was from organizations whose size from (100-500) employees. As for the sector, the highest percentage (37.1\%) was from industrial organizations. The participants were most $(60.3 \%)$ working in organizations which have been established $>20$ years. Table 1 provide a detailed description about the demographic characteristics of the respondents.

Table 1. Respondents demographic profile

\begin{tabular}{|c|c|c|}
\hline Category & Frequency & Percentage $\%$ \\
\hline \multicolumn{3}{|l|}{ Gender } \\
\hline Male & 81 & 53.6 \\
\hline Female & 69 & 45.7 \\
\hline \multicolumn{3}{|l|}{ Employee Age } \\
\hline $20-29$ years & 42 & 27.8 \\
\hline $30-39$ & 67 & 44.4 \\
\hline $40-49$ & 30 & 19.9 \\
\hline 50 years and above & 11 & 7.3 \\
\hline \multicolumn{3}{|l|}{ Educational Level } \\
\hline Bachelor & 90 & 59.6 \\
\hline Master & 44 & 29.1 \\
\hline Doctorate & 9 & 6.0 \\
\hline Others & 7 & 4.6 \\
\hline \multicolumn{3}{|l|}{ Professional Experience } \\
\hline $1-5$ & 48 & 31.8 \\
\hline $6-10$ & 63 & 41.7 \\
\hline $11-15$ & 34 & 26.2 \\
\hline \multicolumn{3}{|c|}{ Organization Years of Establishment } \\
\hline$<10$ years & 23 & 15.2 \\
\hline $11-15$ & 12 & 7.9 \\
\hline $16-20$ & 25 & 16.6 \\
\hline$>20$ & 91 & 60.3 \\
\hline \multicolumn{3}{|l|}{ Sector distribution statistics } \\
\hline Industry & 60 & 39.7 \\
\hline Banking and Finance & 27 & 17.9 \\
\hline Telecommunication \& ICT & 33 & 21.9 \\
\hline Others & 31 & 20.5 \\
\hline \multicolumn{3}{|l|}{ Organizational size } \\
\hline$<100$ & 45 & 29.8 \\
\hline $100-500$ & 46 & 30.5 \\
\hline $500-1000$ & 23 & 15.2 \\
\hline$>1000$ & 37 & 24.5 \\
\hline Total & 151 & 100 \\
\hline
\end{tabular}




\subsection{Descriptive Analysis}

The average mean ranged from 3.3 (Risk Management) to 4 (Resource Control) which means that the respondents had positive response towards the constructs being measured. In addition, the standard deviation for the constructs were ranged between 0.95 and 1.16 which indicate a narrow spread around the mean. The results of the descriptive analysis are shown in Appendix 1 and 2.

\subsection{Hypotheses Testing}

In order to test the hypotheses, multiple regression was used to test the main hypothesis and the sub hypotheses.

H0: There is no statistically significant impact at $(\alpha \leq 0.05)$ of the internal control system on the organizational effectiveness.

Table 2. H0 Model summary

\begin{tabular}{lcccc}
\hline Model & $\mathrm{R}$ & $\mathrm{R}$ Square & Adjusted R Square & Std. Error of the estimate \\
\hline 1. & $.912^{\mathrm{a}}$ & .831 & .825 & .32737 \\
\hline \multicolumn{2}{l}{ a. Predictors: (Constant), Monitoring, Risk Management, Communication, Control Environment, Control Activities } \\
\hline
\end{tabular}

Table 3. H0 ANOVA ${ }^{\text {a }}$ test

\begin{tabular}{llllll}
\hline Model & Sum of Squares & df & Mean Square & F & Sig. \\
\hline Regression & 73.842 & 5 & 14.768 & 137.803 & $000^{\mathrm{b}}$ \\
\hline Residual & 15.004 & 140 & .107 & & \\
\hline Total & 88.845 & 145 & & & \\
\hline $\begin{array}{l}\text { a. Dependent Variable: Organizational Effectiveness } \\
\text { b. Predictors: (Constant), Monitoring, Risk Management, Communication, Control Environment, Control }\end{array}$ \\
Activities
\end{tabular}

According to the multiple regression analysis tables above, the multiple correlation coefficient $\mathrm{R}=0.912$ indicates that there is a strong positive correlation between internal control system (Control Environment, Communication, Risk Management, Control Activities, Monitoring) and Organizational Effectiveness. This means that the independent variables and dependent variable change in the same direction. The results showed that the internal control system accounted for $83.1 \%(\mathrm{R} 2=0.831)$ of the variation in Organizational Effectiveness and that $(83.1 \%)$ of the variance in the organizational effectiveness is significantly explained by the five independent variables of the internal control system. It also means that the higher the internal control system applicability, the higher the applicability of organization effectiveness.

The adjusted $\mathrm{R} 2=0.825$ detects the generalizability of the model. It allows generalizing the results taken from the sample to the whole population. It is noticed that the value of adjusted R2 is very close to the value of R2. If the adjusted R2 is excluded from R2 (0.831 -0.825), the value will be 0.006 . This small value $(0.006)$ indicates that if the model has been fitted when the whole population participates in the study, there will be $0.6 \%$ less variance in the outcome.

According to the ANOVA table, the calculated F-ratio is 137.803 which is $>$ F tabulated (3.8415) at $\alpha<0.05$. In conclusion, there is a statistically significant impact of internal control system (Control Environment, Communication, Risk Management, Control Activities Monitoring) on Organizational Effectiveness. Thus, the null hypothesis will be rejected and the alternative hypothesis is substantiated, which means that there is a statistically significant effect for internal control system on the organizational effectiveness.

The other part of multiple regression analysis is about testing the effect of each predictor included in the model on the dependent variable. The value of standardized beta coefficient can identify the most and least factor of internal control system that affects the organizational effectiveness. 
Table 4. H0 Coefficients

\begin{tabular}{llllll}
\hline \multirow{2}{*}{ Model } & \multicolumn{2}{l}{$\begin{array}{l}\text { Unstandardized } \\
\text { Coefficients }\end{array}$} & $\begin{array}{l}\text { Unstandardized } \\
\text { Coefficients }\end{array}$ & $\mathrm{t}$ & Sig. \\
\cline { 2 - 4 } & $\mathrm{B}$ & \multicolumn{2}{l}{ Std. Error } & \multicolumn{1}{l}{ Beta } & \\
\hline (Constant) & .478 & .136 & & 3.516 & .001 \\
\hline Control Environment & .421 & .059 & .447 & 7.139 & .000 \\
\hline Communication & .001 & .061 & .001 & .011 & .991 \\
\hline Risk Management & .020 & .039 & .027 & .501 & .617 \\
\hline Control Activities & .102 & .064 & .116 & .1596 & .113 \\
\hline Monitoring & .349 & .055 & .395 & 5.917 & .000 \\
\hline a. Dependent Variable: Organizational Effectiveness & & & \\
\hline
\end{tabular}

The standardized beta coefficient indicates the individual contribution of each predictor (independent variable) to the model, if other predictors are held constant. Table 4 shows the standardized coefficients for all internal control factors. As shown in the above table, two of these factors (Control Environment and Monitoring) have statistically significant and relatively high beta coefficients $(0.447$ and 0.395$)$ respectively with significant level of (.000) which is less than (0.05). On the other hand, the other three factors (Communication, Risk management, control activities) was insignificant due to the significance level of $(0.991,0.617,0.113)$ which is greater than $(0.05)$. In terms of the effect of internal control system's factors on organizational effectiveness which depends on the beta value, the (Control Environment) has the highest influence on the dependent variable, then the (Monitoring) factor with beta $44.7 \%$ at level (.000) less than 0.05 .

According to the hypothesis testing rule that was discussed above, the testing results of sub-hypotheses of the main hypothesis are illustrated in the Table 5.

Table 5. Results of testing the sub-hypotheses

\begin{tabular}{ll}
\hline Null Sub-hypothesis & Result \\
\hline $\begin{array}{l}\text { H0-1: There is no statistically significant impact at }(\alpha \leq 0.05) \text { of the Environment on the } \\
\text { organizational effectiveness. }\end{array}$ & Rejected \\
$\begin{array}{l}\text { H0-2: There is no statistically significant impact at }(\alpha \leq 0.05) \text { of the communication on the } \\
\text { organizational effectiveness. }\end{array}$ & Accepted \\
$\begin{array}{l}\text { H0-3: There is no statistically significant impact at }(\alpha \leq 0.05) \text { of the risk management on the } \\
\text { organizational effectiveness. }\end{array}$ & Accepted \\
$\begin{array}{l}\text { H0-4: There is no statistically significant impact at }(\alpha \leq 0.05) \text { of the control activities on the } \\
\text { organizational effectiveness }\end{array}$ & Accepted \\
$\begin{array}{l}\text { H0-5: There is no statistically significant impact at }(\alpha \leq 0.05) \text { of the monitoring on the } \\
\text { organizational effectiveness }\end{array}$ & Rejected \\
\hline
\end{tabular}

The above table shows that the first and fifth null sub-hypotheses of the main hypothesis are rejected and their alternative sub-hypotheses are accepted, because the significance level is less than 0.05 as shown in table 4 . This indicates that there is a statistically significant effect of Control Environment and Monitoring on the organizational effectiveness. On the opposite side, the other three null sub-hypotheses are accepted because the significance level is greater than 0.05 as shown in table 4, this indicates that there is no statistically significant effect of Communication, Risk Management and Control Activities on the organizational effectiveness.

\section{Discussion and Recommendations}

This study has a number of clear implications and recommendations for both managers and decision makers, as follow:

1. In general there is a significant awareness of the importance of internal control system in the Jordanian organizations, and its components are all implemented although in different degrees. 
2. The organizational effectiveness is highly affected by the internal control systems component. This implies that organizational strategies should include enforcing the components of internal control to achieve effectiveness and gain competitive advantage.

3. Environment component descriptive analysis showed that it is an important contributing factor to promote effectiveness; nevertheless, the multiple constituency approach analysis revealed that there is an average recognition and fulfillment of individuals'/groups' different interests, and an average job satisfaction level. In addition, there was average assurance of high personnel competencies, and average accountability promotion in the organizational structure. The multiple regression results showed that this factor had the greatest influence on effectiveness.

In this context, and to further increase the positive impact of the environment factor, the below recommendations are provided:

- Managers and decision makers are encouraged to promote practices that satisfy employees' interests to increase the level of job satisfaction. This would be as a pro-active procedure to prevent this issue to become a future problem.

- Enforcing appropriate human resource policies and practices to leverage competencies by planning specialized training path for employees.

- Adopting and enforcing transparency and justice values through structure reinforcement.

4. Communication component descriptive analysis showed that it is perceived to be of high importance to the effectiveness, it also revealed that although there are different levels of implementation of communication channels (both manually and electronically); there was an average satisfaction of their use. On the other hand, the multiple regression results implied the insignificant effect of communication on the organizational effectiveness. In this context, it is advised that the decision makers must strengthen the communication factor within their organizations by:

- Conducting regular assessment of the currently used channels

- Building communication strategies and policies to enforce communication within the organization.

- Adoption of dynamic and modern communication tools and facilitate their use among employees with minimal costs (ex. Emails, mobile phones, social media).

5. Risk management and Control activities components' descriptive analysis revealed that these factors represent an average importance to the Jordanian organizations. The multiple regression results for those two factors also revealed that they are insignificant to the organizational effectiveness. The importance of this factor was thoroughly discussed in the literature (Dionnem2013), (Little, 2013) and (Accenture, 2013). Akatova et al. (2013) also emphasized the importance of balance between risk management and organizational effectiveness, while Elahi (2013) suggested paying strategic attention to the risk management factor if management was keen on goal achievement.

In the light of the above discussion, risk management and control activities are two extremely important factors in maintaining efficient and reliable business processes, however they are not given the deserved attention as follows:

- Analysis of the risk management factor showed lack of seriousness in the application of Risk Management concept and policies, this is evident by an average awareness, identification, evaluation and review of internal and external risks (Adebayo al., 2009). In this context, Jordanian managers are highly recommended to give this concept a strategic interest and effort to implement its main pillars in their organizations. This should include establishing a specialized unit in the structure capable of building a risk profile containing all internal and external risks. This unit should also review the risk profile periodically and build contingency plans to ensure business continuity (Sparrow, 2014).

- Control activity analysis displayed average employment of both manual and automated control systems that are responsible for early warning of exceptional error occurrence and risk prevention. There is also an average perception of the efficiency of the employed control activities. One of the major and basic matters that need to be urgently tackled is providing personnel with an updated job description. Although being a rule of thumb, this issue was surprisingly of average importance to organizations. Nevertheless, the results also revealed that employees have high apprehension of their responsibilities and related risk tolerance levels. Therefore, it is recommended that personnel are to be granted access to their job description electronically upon request and need, in addition to enforcing the currently applied controls.

6. Monitoring descriptive analysis showed average importance to organizations, this included day-to-day monitoring 
by line managers to guarantee safe and correct implementation of directives. It also includes reviewing the operative information used in management. Nevertheless, the multiple regression results revealed that Monitoring has a highly significant effect on the organizational effectiveness. In this perspective, the researcher recommends considering a business model containing a quality control system which includes quality checks and balances to improve day-to-day monitoring and promote performance elevation.

7. Organizational effectiveness analysis showed that, in general, it is given high importance, which is an indication that organizations pay special attention to the achievement of its goals and pursue to acquire the needed resources. Nevertheless, institutions overlook some important internal and external aspects in the multiple constituency approach that also partially contribute to organizational effectiveness. These aspects are job satisfaction and customer complaints (Kang et al., 2012). It is clear that although an organization is perceived as being effective by its staff, it is slightly ineffective in keeping high job satisfaction and minimum customer complaints.

In this perspective the researcher recommends that Jordanian managers and decision makers promote special incentives occasionally to motivate their staff and increase their institutional loyalty. They can also establish customer loyalty programs to increase customer satisfaction. Also, by implementing the Monitoring and Control Activity recommendations that were suggested previously, customer complaints will decrease over time.

\section{References}

Accenture. (2013). Global risk management study: risk management for an era of greater uncertainty. Retrieved from www.accenture.com/us-en/Pages/insight-global-risk-management-study-2013-eragreater-uncertainty.aspx

Agbejule, A., \& Jokipii, A. (2009). Strategy, control activities, monitoring and effectiveness. Managerial Auditing Journal, 24(6), 500-522. http://dx.doi.org/10.1108/02686900910966503

Alidrisi, H., \& Mohamed, S. (2012). Resource allocation for strategic quality management: A goal programming approach. International Journal of Quality \& Reliability Management, 29(3), 265-283. http://dx.doi.org/10.1108/02656711211216135

Almajali, D. A., Masa'deh, R., \& Tarhini, A. (2016). Antecedents of ERP Systems Implementation Success: A Study on Jordanian Healthcare Sector. Journal of Enterprise Information Management, 29(4), 549-565. http://dx.doi.org/10.1108/JEIM-03-2015-0024

Almajali, D., Mansour, K., \& Maqableh, M. (2016). The Impact of Electronic Supply Chain Management Usage on Firm's Performance. International Journal of Communications, Network and System Sciences, 9(6), 280-293. http://dx.doi.org/10.4236/ijens.2016.96025

Al-Sarayrah, S., Al-Salti, Z., \& Kattoua, T. (2016). The Effect of Culture on Strategic Human Resource Management Practices: A Theoretical Perspective. International Journal of Business Management and Economic Research, 7(4), 704-716.

Al-Syaidh, N. H. J., \& Al-Zu'bi, Z. (2015). Transformational Leadership and its Impact on the Effectiveness of Employees' Behavior in the Public and Private Jordanian Hospitals. Jordan Journal of Business Administration, $11(1), 33-47$

Altamony, H., Tarhini, A., Al-Salti, Z., Gharaibeh, A., \& Elyas, T. (2016). The relationship between Change Management Strategy and Successful Enterprise Resource Planning (ERP) Implementations: A Theoretical Perspective. International Journal of Business Management and Economic Research, 7(4), 690-703.

Appelbaum, S. H., Ulises, I., \& Neville, K. (2005). The creation of an unethical work environment: Organisational outcome-based control systems. Equal Opportunities International, 24(2), 67-83. http://dx.doi.org/10.1108/02610150510788024

Beauchamp-Akatova, E., \& Curran, R. (2013). From initial risk assessments to system risk management. Journal of Modelling in Management, 8(3), 262-289. http://dx.doi.org/10.1108/JM2-01-2011-0008

Büschgens, T., Bausch, A., \& Balkin, D. B. (2013). Organizing for radical innovation-A multi-level behavioral approach. The Journal of High Technology Management Research, 24(2), 138-152. http://dx.doi.org/10.1016/j.hitech.2013.09.004

Davenport, T. H., \& Prusak, L. (1998). Working knowledge: How organizations manage what they know. Harvard Business Press.

Dionne, G. (2013). Risk management: History, definition, and critique. Risk Management and Insurance Review, 16(2), 147-166. http://dx.doi.org/10.1111/rmir.12016 
Elahi, E. (2013). Risk management: the next source of competitive advantage. Foresight, 15(2), 117-131. http://dx.doi.org/10.1108/14636681311321121

Eldridge, S., waarden, J., van der Wiele, T., \& Williams, R. (2013). Management control systems for business processes in uncertain environments. International Journal of Quality \& Reliability Management, 31(1), 66-81. http://dx.doi.org/10.1108/IJQRM-03-2012-0040

El-Masri, M., Orozco, J., Tarhini, A., \& Tarhini, T. (2015). The Impact of IS-Business Alignment Practices on Organizational Choice of IS-Business Alignment Strategies. The 19th Pacific Asia Conference on Information Systems (PACIS 2015), Paper 215, Singapore, 6-9 July 2015.

Hajir, J. A., Obeidat, B. Y., \& Al-dalahmeh, M. A. (2015). The Role of Knowledge Management Infrastructure in Enhancing Innovation at Mobile Telecommunication Companies in Jordan. European Journal of Social Sciences, 50(3), 313-330.

Hanim, F., Haron, H., \& Jantan, M. (2005). Internal auditing practices and internal control system. Managerial Auditing Journal, 20(8), 844-866. http://dx.doi.org/10.1108/02686900510619683

Jacobs, G., van Witteloostuijn, A., \& Christe-Zeyse, J. (2013). A theoretical framework of organizational change. $\begin{array}{llll}\text { Journal of Organizational Change } & \text { 772-792. }\end{array}$ http://dx.doi.org/10.1108/JOCM-09-2012-0137

Jagd, S. (2010). Balancing trust and control in organizations: towards a process perspective. Society and Business Review, 5(3), 259-269. http://dx.doi.org/10.1108/17465681011079482

Jiang, J. Y., \& Liu, C. W. (2015). High performance work systems and organizational effectiveness: The mediating role of social capital. Human Resource Management Review, 25(1), 126-137. http://dx.doi.org/10.1016/j.hrmr.2014.09.001

Kang, B., Jung, J. Y., Wook Cho, N., \& Kang, S. H. (2011). Real-time business process monitoring using formal concept analysis. Industrial Management \& Data Systems, 111(5), 652-674. http://dx.doi.org/10.1108/02635571111137241

Kang, B., Kim, D., \& Kang, S. H. (2012). Periodic performance prediction for real-time business process monitoring. Industrial Management \& Data Systems, 112(1), 4-23. http://dx.doi.org/10.1108/02635571211193617

Kateb, G. A., Swies, R., \& Maqableh, M. (2014). An Investigation on the Critical Factors of Information System Implementation in Jordanian Information Technology Companies. European Journal of Business and Management, 7(36), 11-28

Kennedy, F. A., Kohlmeyer, J. M., \& Parker, R. J. (2009). The roles of organizational justice and trust in a gain-sharing control system. Advances in accounting behavioral research, 12, 1-23. http://dx.doi.org/10.1108/S1475-1488(2009)0000012003

Leung, P., Cooper, B. J., \& Perera, L. (2011). Accountability structures and management relationships of internal audit: An Australian study. Managerial auditing journal, 26(9), 794-816. http://dx.doi.org/10.1108/02686901111171457

Levine, W. S. (1996). The control handbook. CRC press, London: UK.

Little, A.D. (2013). Project risk management - an executive concern. Retrieved from www.adlittle.com

Liu, H., Ke, W., Wei, K. K., Gu, J., \& Chen, H. (2010). The role of institutional pressures and organizational culture in the firm's intention to adopt internet-enabled supply chain management systems. Journal of Operations Management, 28(5), 372-384. http://dx.doi.org/10.1016/j.jom.2009.11.010

Lukas, B. A., Whitwell, G. J., \& Heide, J. B. (2013). Why do customers get more than they need? How organizational culture shapes product capability decisions. Journal of Marketing, 77(1), 1-12. http://dx.doi.org/10.1509/jm.10.0182

Lunenburg, F. C. (2010). Communication: The process, barriers, and improving effectiveness. Schooling, 1(1), 1-11.

Maqableh, M., \& Karajeh, H. (2014). Job Scheduling for Cloud Computing Using Neural Networks. Communications and Network, 6(3), 191-201. http://dx.doi.org/10.4236/cn.2014.63021

Masa'deh, R., Al-Dmour, R. H., \& Obeidat, B. Y. (2015). Strategic IT-Business Alignment as Managers' Explorative and Exploitative Strategies. European Scientific Journal, 11(7), 437-457. 
Masa'deh, R., Al-Dmour, R.H., \& Tarhini, A. (2015). Knowledge Management Strategies as Intermediary Variables between IT-Business Strategic Alignment and Firm Performance. European Scientific Journal, 11(7), 344-368.

Masa'deh, R., Obeidat, B. Y., \& Tarhini, A. (2016). A Jordanian Empirical Study of the Associations Among Transformational Leadership, Transactional Leadership, Knowledge Sharing, Job Performance, and Firm Performance: A Structural Equation Modelling Approach. Journal of Management Development, 35(5), 681-705. http://dx.doi.org/10.1108/JMD-09-2015-0134

Masrek, N., Shahriza, A. K., \& Hussein, R. (2007). Investigating corporate intranet effectiveness: a conceptual framework. Information Management \& Computer Security, 15(3), 168-183. http://dx.doi.org/10.1108/09685220710759522

Neumann, B. R., Cauvin, E., \& Roberts, M. L. (2012). Management control systems dilemma: reconciling sustainability with information overload. Advances in Management Accounting, 20, 1-28. http://dx.doi.org/10.1108/S1474-7871(2012)0000020007

Obeidat, B. Y., Al-Suradi, M., Masa'deh, R., \& Tarhini, A. (2016). The Impact of Knowledge Management on Innovation: An Empirical Study on Jordanian Consultancy Firms. Management Research Review, 39(10), 33-52.

Obeidat, B. Y., Hashem, L., Alansari, I, \& Al-Salti, Z. (2016). The Effect of Knowledge Management Uses on Total Quality Management Practices: A Theoretical Perspective. Journal of Management and Strategy, 7(4).

Obeidat, B. Y., Masa'deh, R., \& Abdallah, A. B. (2014). The Relationships among Human Resource Management Practices, Organizational Commitment, and Knowledge Management Processes: A Structural Equation Modeling Approach. International Journal of Business and Management, 9(3), 9-26. http://dx.doi.org/10.5539/ijbm.v9n3p9

Obeidat, B.Y., Al-Sarayrah, S., Al-Dmour, R. H., Al-Salti, Z., \& Sweis, R. (2016). Cultural Influence on Strategic Human Resource Management Practices: A Jordanian case study. International Business Research, 9(10), 94-114. http://dx.doi.org/10.5539/ibr.v9n10p94

Onumah, J. M., Kuipo, R., \& Obeng, V. A. (2012). Effectiveness of internal control systems of listed firms in Ghana. Accounting in Africa, 12, 31-39. http://dx.doi.org/10.1108/S1479-3563(2012)000012A006

Orozco, J., Tarhini, A., Masa'deh, R., \& Tarhini, T. (2015). A Framework of IS/Business Alignment Management Practices to Improve the Design of IT Governance Architectures. International Journal of Business and Management, 10(4), 1-12. http://dx.doi.org/10.5539/ijbm.v10n4p1

Reginato, L., \& Guerreiro, R. (2013). Relationships between environment, culture, and management control systems. International Journal of Organizational Analysis, 21(2), 219-240. http://dx.doi.org/10.1108/IJOA-02-2011-0477

Rowland, H. (2007). Organizational development: the new buzz word. Strategic Direction, 23(1), 3-14. http://dx.doi.org/10.1108/02580540710716509

Roy, M. H., \& Dugal, S. S. (2005). Using employee gainsharing plans to improve organizational effectiveness. Benchmarking: An International Journal, 12(3), 250-259. http://dx.doi.org/10.1108/14635770510600366

Sarens, G., \& Christopher, J. (2010). The association between corporate governance guidelines and risk management and internal control practices: Evidence from a comparative study. Managerial Auditing Journal, 25(4), 288-308. http://dx.doi.org/10.1108/02686901011034144

Schneider, B., Ehrhart, M. G., \& Macey, W. H. (2013). Organizational climate and culture. Annual review of psychology, 64, 361-388. http://dx.doi.org/10.1146/annurev-psych-113011-143809

Schroeder, H. (2014). An art and science approach to strategic risk management. Strategic Direction, 30(4), 28-30. http://dx.doi.org/10.1108/SD-04-2014-0056

Sera, Y., \& Beaudry S. (2007). Monitoring \& Evaluation. The World Bank Tips, Social Development Department. Retrieved from www.worldbank.org/smallgrantsprogram

Shannak, R. O., Obeidat, B. Y., \& Masadeh, R. M. (2012). Culture and the Implementation Process of Strategic Decisions in Jordan. Journal of Management Research, 4(4), 257-281. http://dx.doi.org/10.5296/jmr.v4i4.2160

Sharma, N., \& Patterson, P. G. (1999). The impact of communication effectiveness and service quality on relationship commitment in consumer, professional services. Journal of services marketing, 13(2), 151-170. http://dx.doi.org/10.1108/08876049910266059 
Skinner, D., \& Spira, L. F. (2003). Trust and control-a symbiotic relationship?. Corporate Governance: The international journal of business in society, 3(4), 28-35. http://dx.doi.org/10.1108/14720700310497096

Slater, S. F., Mohr, J. J., \& Sengupta, S. (2014). Radical product innovation capability: Literature review, synthesis, and illustrative research propositions. Journal of Product Innovation Management, 31(3), 552-566. http://dx.doi.org/10.1111/jpim.12113

Sparrow, P., \& Cooper, C. (2014). Organizational effectiveness, people and performance: new challenges, new research agendas. Journal of Organizational Effectiveness: People and Performance, 1(1), 2-13. http://dx.doi.org/10.1108/JOEPP-01-2014-0004

Su, S., Baird, K., \& Schoch, H. (2015). Management control system effectiveness. Pacific Accounting Review, 27(1), 28-50. http://dx.doi.org/10.1108/PAR-06-2012-0022

Tarhini, A., Arachchilage, N. A. G., \& Abbasi, M.S. (2015). A Critical Review of Theories and Models of Technology Adoption and Acceptance in Information System Research. International Journal of Technology Diffusion (IJTD), 6(4), 58-77. http://dx.doi.org/10.4018/IJTD.2015100104

Thibodeaux, M. S., \& Favilla, E. (1996). Organizational effectiveness and commitment through strategic management. Industrial Management \& Data Systems, 96(5), 21-25. http://dx.doi.org/10.1108/02635579610123307

Tsamenyi, M., \& Cullen, J. (2010). Introduction to management controls and new organisational forms. Journal of Accounting \& Organizational Change, 6(1), 5-8. http://dx.doi.org/10.1108/18325911011025669

Varela-Neira, C., Vázquez-Casielles, R., \& Iglesias, V. (2010). Explaining customer satisfaction with complaint handling. International Journal of Bank Marketing, 28(2), 88-112. http://dx.doi.org/10.1108/02652321011018305

Verhofstadt, E., De Witte, H., \& Omey, E. (2007). Higher educated workers: better jobs but less satisfied?. International Journal of Manpower, 28(2), 135-151. http://dx.doi.org/10.1108/01437720710747965

Wagner, B., \& Svensson, G. (2014). A framework to navigate sustainability in business networks: The transformative business sustainability (TBS) model. European Business Review, 26(4), 340-367. http://dx.doi.org/10.1108/EBR-12-2013-0146

Xenidis, Y., \& Theocharous, K. (2014). Organizational health: definition and assessment. Procedia Engineering, 85, 562-570. http://dx.doi.org/10.1016/j.proeng.2014.10.584

Appendix A. Mean and standard deviation for Internal Control System

\begin{tabular}{lll}
\hline Item & Mean & SD \\
\hline Control Environment (Cronbach Alpha = .920) & 3.86 & 1.13 \\
$\begin{array}{l}\text { My organization offers regular services / products, and is satisfied with the efficiency of its } \\
\text { present products and markets. }\end{array}$ & 3.96 & .946 \\
My organization endeavour to respond to market needs rapidly & 4.10 & .901 \\
$\begin{array}{l}\text { My organization has plans to lay new products/services in the future. } \\
\text { Management ensures the competencies of its personnel by establishing appropriate human }\end{array}$ & 4.12 & 1.04 \\
resource policies and practices. & & 1.18 \\
$\begin{array}{l}\text { Employees' morale and attitude towards their jobs contributes to their achievement and } \\
\text { efficiency in work. }\end{array}$ & 4.05 & 1.11 \\
$\begin{array}{l}\text { Management's philosophy, style and supportive attitude contribute to the achievement of } \\
\text { objectives and goals }\end{array}$ & 3.90 & 1.10 \\
$\begin{array}{l}\text { Management supports the ethical values and integrity in the organization } \\
\text { The organizational structure gives the managers the assurance that the planned programs } \\
\text { meet the objectives. }\end{array}$ & 3.96 & 1.02 \\
$\begin{array}{l}\text { The organizational structure is clear and promotes accountability. } \\
\text { Communication (Cronbach Alpha }=.922)\end{array}$ & 3.60 & 1.07 \\
\hline
\end{tabular}


There are efficient communication channels throughout my organization

Management and staff use the available communication channels to communicate relevant information to the right people at the right time.

My organization uses electronic communication channels.

4.23

Management uses the available communication channels to inform employees of their duties and responsibilities

Employees use the available communication channels to provide suggestions for 3.76 improvement to the management

My organization established efficient communication with its suppliers and customers.

I am satisfied with the means of communication used in my organization.

Risk Management (Cronbach Alpha $=.940)$

There is a general awareness of the importance of creating a risk profile for all aspects in the

The risk profile in my organization includes the significance, likelihood and cause of all risks

The policies on risk management in the organization clearly describe the roles and 3.35 accountabilities of the board, management, and any internal audit formation.

A risk management system is established and implemented in my organization

Management has plans to prevent/reduce/avoid the internal and external risks

There are functional controls in the organization's processes which give warning whenever

In the definition of tasks special attention is paid to authorization and the special demands of $\quad 3.69$ the tasks

The entire personnel have updated job descriptions.

My organization employs efficient and effective control activities that reduce /prevent the

There is active control of how the personnel implement the operating instructions issued by performance over time.

The internal controls are assessed and reviewed periodically to guarantee its effectiveness 
Appendix B. Mean and standard deviation of organizational effectiveness

\begin{tabular}{|c|c|c|}
\hline Item & Mean & SD \\
\hline Goal Approach $($ Cronbach Alpha $=.914)$ & 3.79 & .95 \\
\hline $\begin{array}{l}\text { Management has a reasonable assurance that the structure will support planned goals } \\
\text { and objectives }\end{array}$ & 3.76 & .99 \\
\hline $\begin{array}{l}\text { There is a comprehensive integration of activities and efforts of people in the } \\
\text { organization to ensure the achievement of goals and objectives. }\end{array}$ & 3.71 & .92 \\
\hline $\begin{array}{l}\text { Effective operations within my organization lead to quality products/services that are } \\
\text { consistent with the organization's mission. }\end{array}$ & 3.79 & 1.15 \\
\hline My organization is successful in achieving its objectives & 3.94 & 1.19 \\
\hline $\begin{array}{l}\text { Service recipients' studies indicate a high level of satisfaction of our } \\
\text { products/services }\end{array}$ & 3.76 & .88 \\
\hline Resource control approach $($ Cronbach Alpha $=.896)$ & 4.00 & .96 \\
\hline $\begin{array}{l}\text { My organization is capable of attracting the needed resources to produce its } \\
\text { products/services }\end{array}$ & 4.09 & .89 \\
\hline My organization ensures its staff's adherence to laws, regulations and contracts & 4.07 & .96 \\
\hline $\begin{array}{l}\text { Management directives and decisions rely on a timely financial and managerial } \\
\text { reporting system. }\end{array}$ & 3.98 & 1.09 \\
\hline Resources are being safeguard against loss due to waste, abuse, errors and fraud. & 3.88 & 1.03 \\
\hline Multiple constituency approach $($ Cronbach Alpha $=.864)$ & 3.60 & .98 \\
\hline My organization survived against its competitors over the last few years & 4.18 & .96 \\
\hline Different interests of individuals /groups are recognized and fulfilled. & 3.32 & 1.15 \\
\hline $\begin{array}{l}\text { Periodical surveys indicate a reasonable job satisfaction among employees in my } \\
\text { organization }\end{array}$ & 3.25 & 1.11 \\
\hline Periodical surveys indicate high customer satisfaction of our products/services & 3.68 & 0.94 \\
\hline There is a noticeable decline in the number of complaints from our clients. & 3.57 & 0.93 \\
\hline
\end{tabular}

